\title{
Contributions of SST Anomalies in the Indo-Pacific Ocean to the Interannual Variability of Tropical Cyclone Genesis Frequency over the Western North Pacific
}

\author{
RUIFEN ZHAN \\ Shanghai Typhoon Institute of China Meteorological Administration, Shanghai, and State Key \\ Laboratory of Severe Weather, Chinese Academy of Meteorological Sciences, Beijing, China \\ YUQING WANG \\ State Key Laboratory of Severe Weather, Chinese Academy of Meteorological Sciences, Beijing, China, and International \\ Pacific Research Center and Department of Atmospheric Sciences, School of Ocean and Earth Science and \\ Technology, University of Hawai'i at Mānoa, Honolulu, Hawaii
}

JIUWEI ZHAO

International Pacific Research Center and Department of Atmospheric Sciences, School of Ocean and Earth Science and Technology, University of Hawai'i at Mānoa, Honolulu, Hawaii

(Manuscript received 10 July 2018, in final form 6 March 2019)

\begin{abstract}
This study attempts to evaluate quantitatively the contributions of sea surface temperature (SST) anomalies in the Indo-Pacific Ocean to the interannual variability of tropical cyclone (TC) genesis frequency (TCGF) over the western North Pacific (WNP). Three SST factors in the Indo-Pacific Ocean are found to play key roles in modulating the interannual variability of WNP TCGF. They are summer SST anomaly in the east Indian Ocean (EIO), the summer El Niño-Southern Oscillation Modoki index (EMI), and the spring SST gradient (SSTG) between the southwestern Pacific and the western Pacific warm pool. Results show that the three factors together can explain $72 \%$ of the total variance of WNP TCGF in the typhoon season for the period 1980-2015. Among them, the spring SSTG and the summer EIO contribute predominantly to the interannual variability of TCGF, followed by the summer EMI, with respective contributions being $39 \%$, $38 \%$, and $23 \%$. Further analysis shows that the summer EMI was affected significantly by the spring SSTG and thus had a relatively lower contribution to the TCGF than the spring SSTG. In addition, a statistical model is constructed to predict the WNP TCGF in the typhoon season by a combination of the May EIO and the spring SSTG. The new model can reproduce well the observed WNP TCGF and shows an overall better skill than the ECMWF Seasonal Forecasting System 5 (SEAS5) hindcasts. This statistical model provides a good tool for seasonal prediction of WNP TCGF.
\end{abstract}

\section{Introduction}

Tropical cyclone (TC) ${ }^{1}$ activity over the western North Pacific (WNP) exhibits significant interannual variability (e.g., Chan 1985, 2000; Chen et al. 1998; Chia and Ropelewski 2002; Wang and Chan 2002; Camargo and

\footnotetext{
${ }^{1}$ All abbreviations used in the main text are listed in the appendix.

Corresponding author: Prof. Yuqing Wang, yuqing@hawaii.edu
}

Sobel 2005; Zhan et al. 2011a). Better understanding of the interannual relationship between TC activity and climate variations is vital to conduct skillful seasonal forecasts of TC activity. Over the past decades, climate variation that controls TC activity has been extensively explored and the involved physical mechanisms have also been investigated [see a review by Zhan et al. (2012)]. Among them, the impacts of sea surface temperature (SST) anomalies (SSTAs) in the Indo-Pacific Ocean on TC activity over the WNP have received the most attention.

El Niño-Southern Oscillation (ENSO), the strongest interannual climate signal in the tropics, has been shown 
to exert critical impacts on TC activity over the WNP. In general, the warm phase (El Niño) of ENSO leads to an eastward displacement of the mean location of TC genesis over the WNP (e.g., Wang and Chan 2002; Chia and Ropelewski 2002). Accordingly, TCs formed in the southeast quadrant travel longer and tend to be more intense in El Niño years than in La Niña years (Chia and Ropelewski 2002; Camargo and Sobel 2005; Chen et al. 2006; Chan 2007). The stronger the ENSO events are, the more prominent their impacts become (Wang and Chan 2002; Zhan et al. 2018). Although there is no significant correlation between the TC genesis frequency (TCGF) in the entire WNP basin and the Niño-3.4 index (Ramage and Hori 1981; Lander 1994; Wang and Chan 2002; Chen et al. 2006; Zhan et al. 2011a), a significant positive correlation between ENSO Modoki (also often central Pacific ENSO) and TCGF over the WNP has been revealed (Chen and Tam 2010; Wu et al. 2018). It is suggested that the relationship between ENSO and TCGF over the WNP is closely associated with the ENSO warming pattern (Kim et al. 2011).

Apart from ENSO, the SSTA in the east Indian Ocean (EIO) has been found to affect significantly TCGF over the WNP (Du et al. 2011; Zhan et al. 2011a,b; Tao et al. 2012). The prolonged SST warming over the EIO is favorable for a sharp decrease in TCGF during the typhoon season. More recently, the SSTA in the southwest Pacific has been shown to affect WNP TCGF significantly as well (Zhou and Cui 2011; Zhan et al. 2013). There is a significant negative correlation between the SSTA over the southwest Pacific east of Australia (SWP) and the WNP TCGF. This SWP SSTA can be replaced by the SST gradient (SSTG) between the southwest Pacific and the western Pacific warm pool (WWP) in spring (Zhan et al. 2013; Zhan and Wang 2016). The positive SSTG anomaly in boreal spring can produce an anomalous cross-equatorial pressure gradient with an anomalous tropical easterly, leading to a weakened monsoon trough and reduced TCGF over the WNP. Some other factors associated with the SSTAs in the Indo-Pacific Ocean may affect the interannual variability of WNP TCGF as well, such as the North Pacific Victoria mode (Pu et al. 2019) and Pacific meridional mode (Zhang et al. 2016).

The interannual variability of TCGF is modulated by a combination of all possible factors and multiple concurrent forcings, which is vital but most challenging for seasonal prediction of TCGF. However, most previous studies have focused only on the response of TC activity to one of the SST factors, and the relative importance and contributions to the interannual variability of TCGF are unclear. In this study, we will focus on the SST factors in the Indo-Pacific Ocean and will

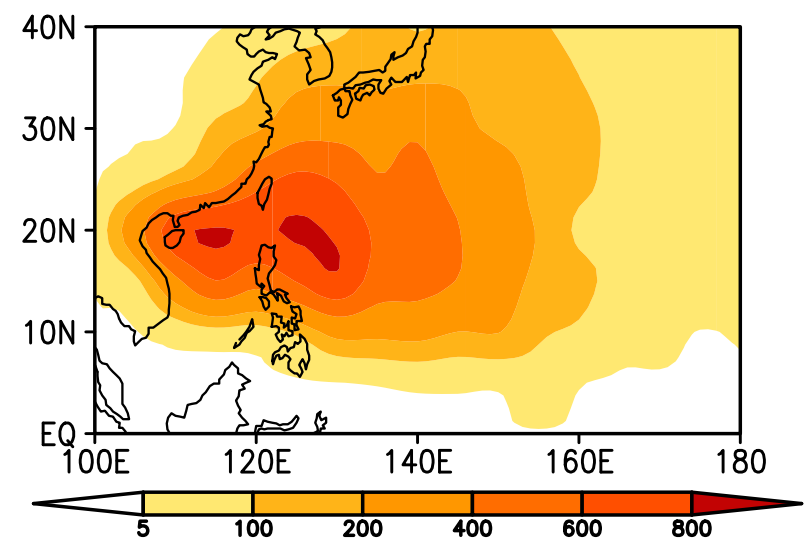

FIG. 1. Spatial distribution of occurrence frequency of TCs over the WNP in the 36 typhoon seasons during 1980-2015 in each $5^{\circ}$ lon $\times 5^{\circ}$ lat grid box.

determine their individual and combined contributions to the interannual variability of TCGF over the WNP. We will also construct a new statistical model, which can be used to provide skillful seasonal prediction of TCGF over the WNP.

The remainder of the paper is organized as follows. Section 2 describes the datasets and analysis methods used in this study. The statistical relationship between various SSTAs in the Indo-Pacific Ocean and the WNP TCGF is examined and the key SST factors are selected in section 3. Physical links between the key SST factors and WNP TCGF are reviewed in section 4. Section 5 evaluates the relative importance/contributions and the combined impact of individual SST factors. In section 6 , a new statistical model for seasonal prediction of TCGF over the WNP is introduced and its skill is demonstrated with both hindcasts and reforecasts. Finally, the main conclusions are summarized in section 7 .

\section{Data and methods}

\section{a. Data}

The 6-hourly best track TC data over the WNP (which is defined as $0^{\circ}-40^{\circ} \mathrm{N}, 100^{\circ} \mathrm{E}-180^{\circ}$ ) for the period 1980-2015 were derived from the Shanghai Typhoon Institute of the China Meteorological Administration (CMA). The best track TC datasets from the Japan Meteorological Agency (JMA) and the Joint Typhoon Warning Center (JTWC) were used to confirm the robustness of the results based on the CMA best track dataset. We focused on TCs with at least tropical storm (TS) intensity (with maximum sustained 10-m wind speed $\geq 17 \mathrm{~m} \mathrm{~s}^{-1}$ ) that occurred in the typhoon season from June to October each year during 1980-2015. Figure 1 shows the geographical distribution of the 
occurrence frequency of TCs referred to in this study. The TC occurrence frequency was calculated in each $5^{\circ}$ longitude $\times 5^{\circ}$ latitude box. When a TC passes a grid box, TC occurrence in this box is counted once. The maximum frequency of occurrence can be used to infer the prevailing tracks. A maximum zone is located roughly within $15^{\circ}-25^{\circ} \mathrm{N}, 105^{\circ}-145^{\circ} \mathrm{E}$ with two centers in the South China Sea (SCS) and the northeast of Philippines, respectively. The WNP TCs are characterized by three prevailing tracks: moving westward into the SCS, moving northwestward affecting eastern China, and recurving northeastward affecting the Korean Peninsula and Japan.

We also employed the monthly extended reconstructed SST (ERSST v5) analyses from the National Oceanic and Atmospheric Administration (NOAA; Smith and Reynolds 2004), and the monthly atmospheric reanalysis data from the National Centers for Environmental Prediction (NCEP)-National Center for Atmospheric Research (NCAR) dataset (Kalnay et al. 1996). The ECMWF Seasonal Forecasting System 5 (SEAS5) hindcast data were used to compare with our new statistical model developed in this study. The TCs in the SEAS5 data are detected using the tracker described in Vitart et al. (1997) and the statistics of the detected TCs are calibrated using the seasonal reforecasts. SEAS5 displays generally higher skill over the WNP than its earlier version, SEAS4, in both TC climatology and interannual variability. More details about the SEAS5 and its performance in seasonal prediction of TC activity can be found in the SEAS5 user guide (https:// www.ecmwf.int/sites/default/files/medialibrary/2017-10/ System5_guide.pdf).

\section{b. Methods}

Following Zhan et al. (2011a), the EIO SSTA index was defined as the SSTA averaged in the region $10^{\circ} \mathrm{S}-22.5^{\circ} \mathrm{N}, 75^{\circ}-100^{\circ} \mathrm{E}$. The ENSO Modoki index (EMI) was calculated based on the definition described in Ashok et al. (2007). The SSTG index was defined as the difference in SSTAs between the SWP $\left(40^{\circ}-20^{\circ} \mathrm{S}\right.$, $\left.160^{\circ} \mathrm{E}-170^{\circ} \mathrm{W}\right)$ and the WWP $\left(0^{\circ}-16^{\circ} \mathrm{N}, 125^{\circ}-165^{\circ} \mathrm{E}\right)$ as in Zhan et al. (2013). The regions used to define the above three SSTA indices have been marked in Fig. 2. Moreover, in this study, the spring means the 3-month average over March-May and the summer means the 3-month average over June-August.

To quantify the relative importance of key SST factors in the Indo-Pacific Ocean in modulating TCGF over the WNP, the Lindeman, Merenda, and Gold method (LMG; Lindeman et al. 1980) of the relaimpo package (Grömping 2006) within the R environment for statistical computing (R Core Team 2014) was employed. In this study, the WNP TCGF is defined as the total number of TCs formed in the $\mathrm{WNP}\left(0^{\circ}-40^{\circ} \mathrm{N}, 100^{\circ} \mathrm{E}-180^{\circ}\right)$ during the typhoon season. The response amplitudes of TCGF to the key SST factors were also estimated using the equilibrium feedback assessment (EFA; Frankignoul et al. 1998) and the generalized EFA (GEFA) methods (Liu et al. 2008). The EFA method was used to estimate the atmospheric feedback to any single SST index (Liu and Wu 2004). As an extension, the GEFA method can be used to distinguish the impacts of different SST factors or modes on atmospheric variability from observations. The confidence level of the feedback response coefficient of these two methods was tested using the Monte Carlo method. The GEFA method has been widely applied in recent years (Jiang et al. 2014; Yu et al. 2016a). Full formulations and the details of EFA and GEFA can be found in Frankignoul et al. (1998) and Liu et al. (2008), respectively.

The effect of one SST factor $A$ was abstracted from the other factor $B$ based on the following method developed by Ashok et al. (2003):

$$
I_{R B}=I_{B}-r\left(I_{B}, I_{A}\right) O^{\prime} \tilde{I}_{A},
$$

where $I_{A}$ stands for index $A, \tilde{I}_{A}$ denotes the normalized $I_{A}, O^{\prime}$ is the standard deviation of index $B\left(I_{B}\right)$, and $\left(I_{B}, I_{A}\right)$ denotes the correlation coefficient between indices $B$ and $A$. Thus, $I_{R B}$ is the remainder of index $B$ with the signal $A$ removed.

In addition, the multivariate empirical orthogonal function (MV-EOF; Wang 1992) was used to examine the coupled modes of the key SST factors in affecting TCGF over the WNP. A multiple linear regression system (with multiple predictors) was used to develop the statistical model following Wang et al. (2009). To test the predictive capability of the newly developed statistical model, the leave-one-out cross-validation method (Michaelsen 1987) was used to conduct hindcast for TCGF over the WNP.

\section{Identification of key SST factors in the Indo-Pacific Ocean}

To discriminate the key SST factors in the IndoPacific Ocean predominantly modulating the interannual variability of WNP TCGF, we first examined the correlations between summer (June-August) SSTAs and TCGF in the typhoon season (June-October) over the WNP. Figure 2 shows the spatial distributions of the correlation coefficients between them during 1980-2015 from the original data and from the data with the linear trend removed, respectively. We take a first look at the CMA TC best track data (Figs. 2a and 2d). In the original data (Fig. 2a), the WNP TCGF exhibits significant 

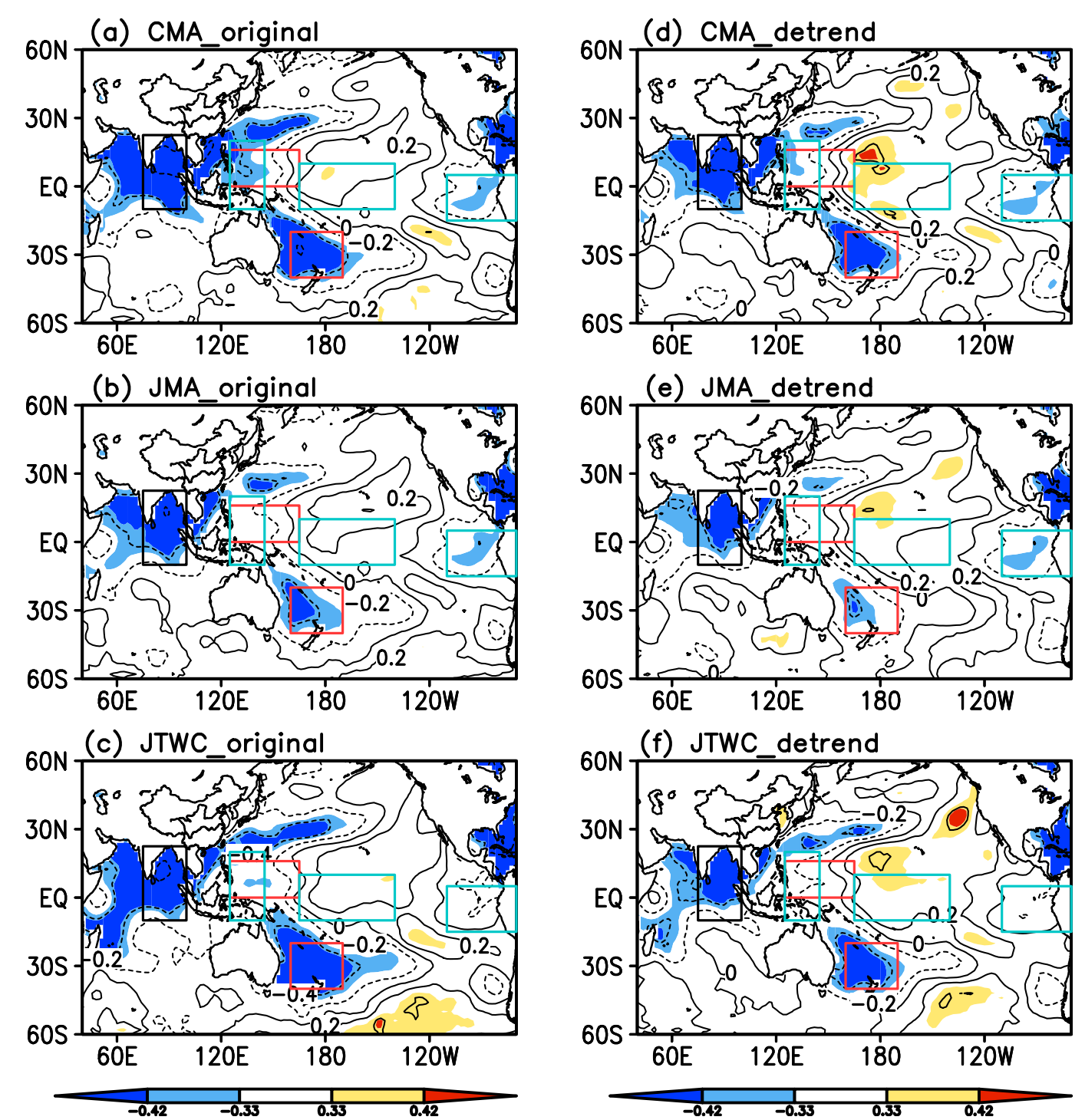

FIG. 2. Correlation coefficients between summer (JJA)-mean SST and TCGF over the WNP in the typhoon season [June-October (JJASO)] from the (a),(d) CMA, (b),(e) JMA, and (c),(f) JTWC TC best track datasets during 1980-2015 based on (left) the original data and (right) the data with the linear trend removed. The range for statistical significance at the $95 \%(99 \%)$ confidence level is $\pm 0.33( \pm 0.42)$. The boxes indicate the primary regions for calculating the three key SSTA indices.

negative correlations with SSTAs in the Indian Ocean, the southwest Pacific east of Australia (SWP; $40^{\circ}-20^{\circ} \mathrm{S}$, $160^{\circ} \mathrm{E}-170^{\circ} \mathrm{W}$ ), and the tropical western Pacific. Positive but statistically insignificant correlations are located in the tropical central Pacific (CP). With the linear trend removed (Fig. 2d), the negative correlations in the above three regions still remain significant but with some changes. Now the area with negative correlations in the Indian Ocean is mainly confined in the EIO and that in tropical western Pacific is slightly shrunk to the SCS and near the Philippines. Meanwhile, the positive correlation in the $\mathrm{CP}$ becomes statistically significant.
Similar correlations are obtained using the JMA and the JTWC best track TC datasets (Figs. 2b,c,e,f) except in the tropical western Pacific where the area with negative correlation becomes very narrow, in particular in the case with the linear trend removed. Note that since strong interaction exists between TC activity and the local SST (Wang and Chan 2002), summer SSTA in the tropical western Pacific should not be a key factor and thus some discrepancies among the three best track TC datasets would not alter our main conclusions. In fact, we also calculated the correlations between SSTAs during September-October and TCGF in the typhoon 
season over the WNP. We found that correlations of WNP TCGF with the SSTAs over the Indian Ocean and the Pacific are higher during summer than during September-October (figure not shown). As a result, we focus on the summer SSTAs in this study.

The above significant positive correlation over the $\mathrm{CP}$ has been shown to be related to ENSO Modoki, while the negative correlations with the EIO and SWP SSTAs have been well documented in previous studies (Chen and Tam 2010; Zhan et al. 2011a,b; Zhou and Cui 2011). It should be noted that the spring (March-May) SSTG is a better predictor for the interannual variability of WNP TCGF than the summer SWP. There are two main reasons for this. On the one hand, there are significant positive correlations between the spring SSTG and the SWP SSTAs from spring through the whole typhoon season (figure not shown). This means that the spring SSTG can include the majority of information of the summer SWP SSTA due to the persistence. On the other hand, the spring SSTG anomaly can excite an SSTA in the equatorial central Pacific by inducing local upwelling (downwelling) and raising (reducing) the thermocline in the east as will be further demonstrated in the next section. Previous studies have shown that the equatorial CP SSTA plays an important role in modulating the WNP TCGF (Chen and Tam 2010; Kim et al. 2011; Zhan et al. 2014). The development and strengthening through the typhoon season in the equatorial CP SSTA further enhance the impact of the boreal spring SSTG anomaly on the atmospheric circulation and TC genesis over the WNP.

Based on the above correlation analysis, we can select three SST factors in the Indo-Pacific Ocean key to the interannual variability of WNP TCGF, including the summer EIO SSTA, the summer ENSO Modoki, and the spring SSTG. Since all three best track TC datasets show consistent correlations with the three SST factors, only the CMA best track TC dataset will be used in most of our following discussion. Figure 3 shows the time series of WNP TCGF in the typhoon season during 1980-2015 based on the CMA best track TC data and the three SST factors identified above. As expected, outof-phase relationships of the TCGF with the EIO index and the SSTG index are prominent, with the correlation coefficients of -0.62 and -0.71 , respectively, and an inphase relationship exists between the TCGF and the EMI, with a correlation coefficient of 0.58 . All three correlations are significant well above the $95 \%$ confidence level. This means that the individual variations of the EIO, EMI, and SSTG alone can explain as much as $38.4 \%, 33.6 \%$, and $50.4 \%$ of the total variance of interannual variability in WNP TCGF during 1980-2015, respectively.
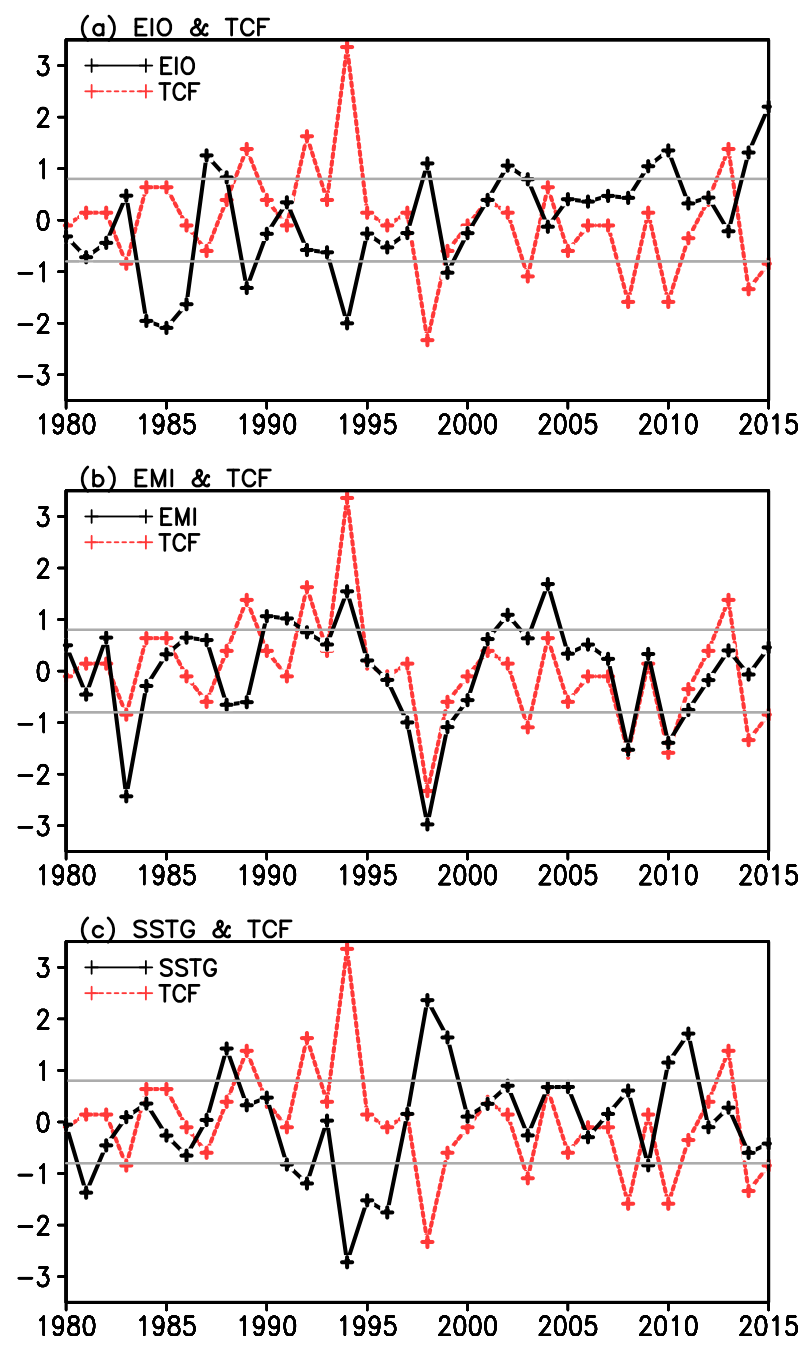

FIG. 3. Time series of the normalized TCGF over the WNP in the typhoon season and (a) the summer EIO index, (b) the summer EMI index, and (c) the spring SSTG index during 1980-2015.

To confirm the robustness of the above relationships, Table 1 lists the correlation coefficients between the WNP TCGF from the three best track TC datasets and the three key SST factors using the original data, the data with the linear trend removed, and the data with only the interannual variability retained by removing the decadal/interdecadal variability using a nine-point Gaussian-type filter. For the original data, the three best track datasets show similar results, with significant negative correlations of the TCGF with the EIO index and the SSTG index and significant positive correlation with the EMI index, all significant well above the $95 \%$ confidence level. Results with the linear trend removed and with the interannual variability retained are similar, suggesting that the three SST factors significantly modulated the interannual variability of TCGF over the 
TABLE 1. Correlation coefficients between the TCGF over the WNP in the typhoon season from the three TC best track datasets and the three SST factors (summer EIO, summer EMI, and spring SSTG) during 1980-2015 based on the original data, the data with the line trend removed, and the data with the interannual variability remained using a nine-point Gaussian-type filter. Values appear as CMA/JMA/ JTWC. Correlation coefficients significant at and above the $99 \%$ confidence level $( \pm 0.42)$ are shown in boldface. Note that all correlations shown in Table 1 are significant above the $99 \%$ confidence level.

\begin{tabular}{lccc}
\hline \hline & Original data & Detrended data & Interannual data \\
\hline EIO (summer) & $-\mathbf{0 . 6 2} /-\mathbf{0 . 5 5} /-\mathbf{0 . 5 9}$ & $-\mathbf{0 . 5 8} /-\mathbf{0 . 5 1} /-\mathbf{0 . 5 3}$ & $-\mathbf{0 . 6 5} /-\mathbf{0 . 5 8} /-\mathbf{0 . 5 9}$ \\
EMI (summer) & $\mathbf{0 . 5 8 / 0 . 5 1 / 0 . 4 4}$ & $\mathbf{0 . 5 8} / \mathbf{0 . 5 1} / \mathbf{0 . 4 5}$ & $\mathbf{0 . 5 6} / \mathbf{0 . 4 8} / \mathbf{0 . 4 5}$ \\
SSTG (spring) & $-\mathbf{0 . 7 1} /-\mathbf{0 . 6 5} /-\mathbf{0 . 5 6}$ & $-\mathbf{0 . 7 2} /-\mathbf{0 . 6 6} /-\mathbf{0 . 5 7}$ & $-\mathbf{0 . 6 8} /-\mathbf{0 . 5 9} /-\mathbf{0 . 5 9}$ \\
\hline
\end{tabular}

WNP and the relationships are robust and independent of the best track dataset used.

\section{Physical links between the key SST factors and WNP TCGF}

To provide a physical basis for the analyses in the following two sections and confirm the meaningful physical links between the key SST factors identified in section 3 and WNP TCGF, we give an overview on how the three key SST factors affect the atmospheric circulation and thus TCGF over the WNP in this section. In particular, we try to integrate previous understanding to form a relatively complete picture for the interplay of the three key SST factors in modulating the interannual variability of TCGF over the WNP.

First, we have done a regression analysis to elucidate how the low-level winds respond to each of the three key
SST factors. Figure 4 shows the regressed seasonal-mean $850-\mathrm{hPa}$ wind fields in the typhoon season with respect to, respectively, the EIO index, the EMI index, and the spring SSTG index during 1980-2015. Since the impact of SSTG on WNP TCGF is triggered in spring and maintained through the whole typhoon season, the regressed seasonal-mean $850-\mathrm{hPa}$ wind field in spring with respect to the spring SSTG index is also presented in Fig. 4c. It is clear that the responses of the low-level winds in the typhoon season to the EIO and spring SSTG are similar, with uniform tropical easterly anomalies extending from the date line to the Bay of Bengal and an anomalous anticyclone covering most of the WNP. These low-level circulation anomalies induced by the EIO SSTA and the spring SSTG anomaly are unfavorable for TC genesis in the typhoon season over the WNP. Moreover, it can be seen that the anomalous low-level winds induced by the spring SSTG seem
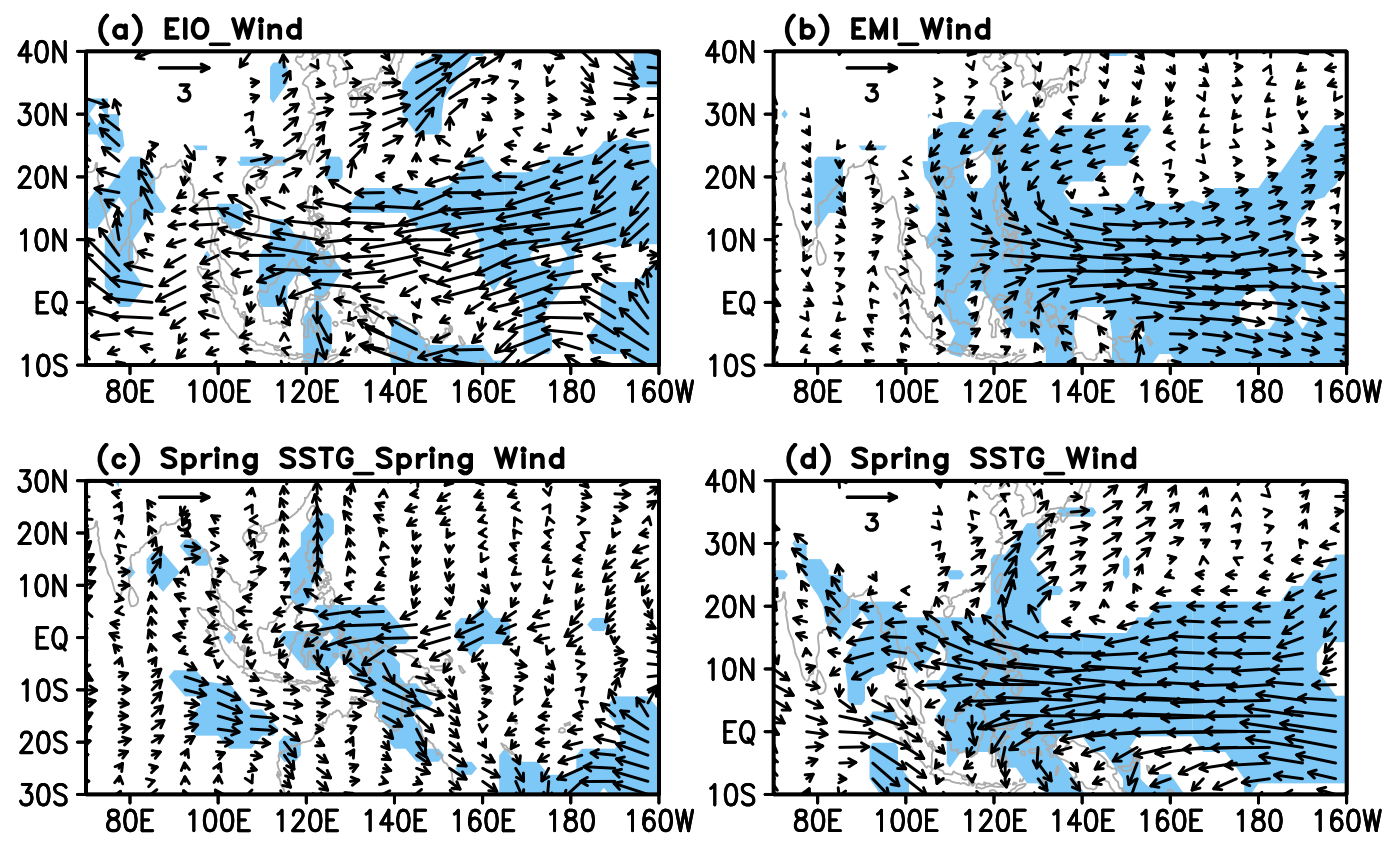

FIG. 4. Regressed seasonal-mean 850 -hPa wind fields (vectors; $\mathrm{m} \mathrm{s}^{-1}$ ) with respect to (a) the EIO index, (b) the EMI index, and (c),(d) the spring SSTG index during 1980-2015. In (a), (b), and (d), the 850-hPa wind fields were averaged in the typhoon season, while in (c) the $850-\mathrm{hPa}$ wind fields were averaged in spring. Areas that are statistically significant at the $95 \%$ confidence level based on the $\mathrm{F}$ test are shaded. 


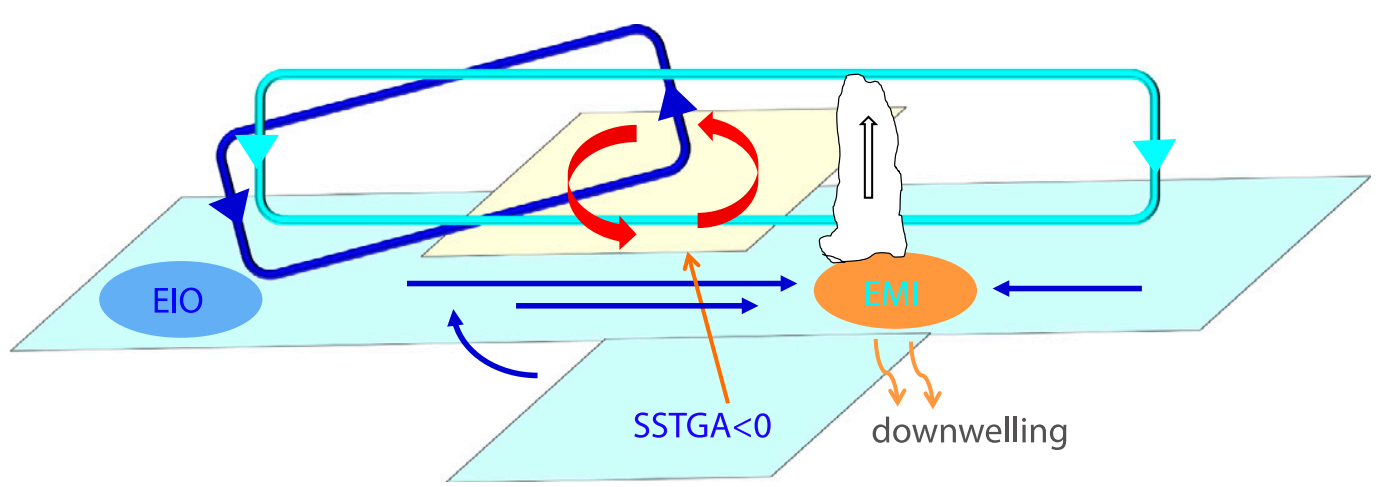

FIG. 5. Schematic diagram showing the responses of the large-scale atmospheric circulation fields over the WNP to the cold EIO, the negative SSTG anomaly (SSTGA), and El Niño Modoki (EMI). The details can be found in the text.

to have been triggered in spring, which is consistent with the results of Zhan et al. (2013). In sharp contrast, the El Niño Modoki event is more likely to induce anomalous tropical westerlies and an anomalous cyclone over the WNP. However, the induced anomalous tropical westerlies rapidly weaken near the Philippines and become negligible over the western SCS. This suggests that the El Niño Modoki event is favorable for WNP TC genesis but its effect is confined to the WNP east of the SCS.

The above results based on the regressed low-level winds are generally consistent with those reported in previous studies (Chen and Tam 2010; Zhan et al. 2011a,b; Zhan et al. 2013). Furthermore, how each key SST factor affects the atmospheric circulation and thus TCGF over the WNP is synthesized schematically in Fig. 5. For the sake of brevity, we just illustrate situations with the cold EIO, the El Niño Modoki, and the negative SSTG anomaly (SSTGA) in Fig. 5, and vice versa for the situations with the warm EIO, the La Niña Modoki, and the positive SSTGA.

Based on observational analyses and numerical modeling experiments, Zhan et al. (2011a,b) revealed that the EIO SSTA affects the WNP TCGF by modulating the WNP summer monsoon and the activity of the equatorial Kelvin waves. On the one hand, the cold EIO increases the land-sea thermal contrast, inducing stronger than normal WNP summer monsoon and its associated monsoon trough, and thus enhancing TCGF over the WNP. On the other hand, the cold EIO SSTA can trigger a cold equatorial Kelvin wave to the east over the WNP, leading to anomalous equatorial westerlies and anomalous cyclonic circulation in the lower troposphere in the tropics over the WNP off the equator, producing dynamic and thermodynamic conditions favorable for TC genesis over the WNP TC genesis region.

El Niño Modoki is featured by warm SSTA maximized in the equatorial CP (Ashok et al. 2007). The response to the anomalous heating source associated with the summer warm SSTA is an anomalous low-level large-scale cyclonic circulation in the typhoon season over most of the WNP (Figs. 4b and 5). This anomalous low-level circulation response can be interpreted dynamically as the meridional dispersion of forced equatorial Rossby waves (Gill 1980; Chen and Tam 2010). Therefore, the summer El Niño Modoki events are favorable for TC geneses over the WNP.

Based on previous studies by Zhan et al. (2013) and Zhao et al. (2016), the spring SSTG anomaly affects the WNP TCGF by two mechanisms. The first is related to the persistence of the SSTG itself. Namely, in spring, the negative SSTG anomaly leads to a cross-equatorial pressure gradient, which forces anomalous northward cross-equatorial flow and tropical westerlies in the lower troposphere over the WNP (as we can see from Figs. 4c and 5). This observed response was also demonstrated by several sensitivity experiments using a regional climate model in Zhan et al. (2013). The pattern triggered by the spring SSTG can persist through the typhoon season and provides favorable conditions for TC genesis over the WNP. The second mechanism is associated with the tropical air-sea interaction. In the typhoon season, the equatorial westerlies in response to the negative SSTG anomaly act to warm the equatorial CP by inducing local downwelling and reducing the thermocline in the east. This warm SSTA further enhances the equatorial westerlies and thus TC genesis over the WNP.

\section{Individual and combined contributions of the key SST factors}

In the last two sections, three SST factors over the Indo-Pacific Ocean that are key to the interannual variability of WNP TCGF have been identified and the related physical mechanisms have been reviewed. Natural questions arise as to what extent these three key 

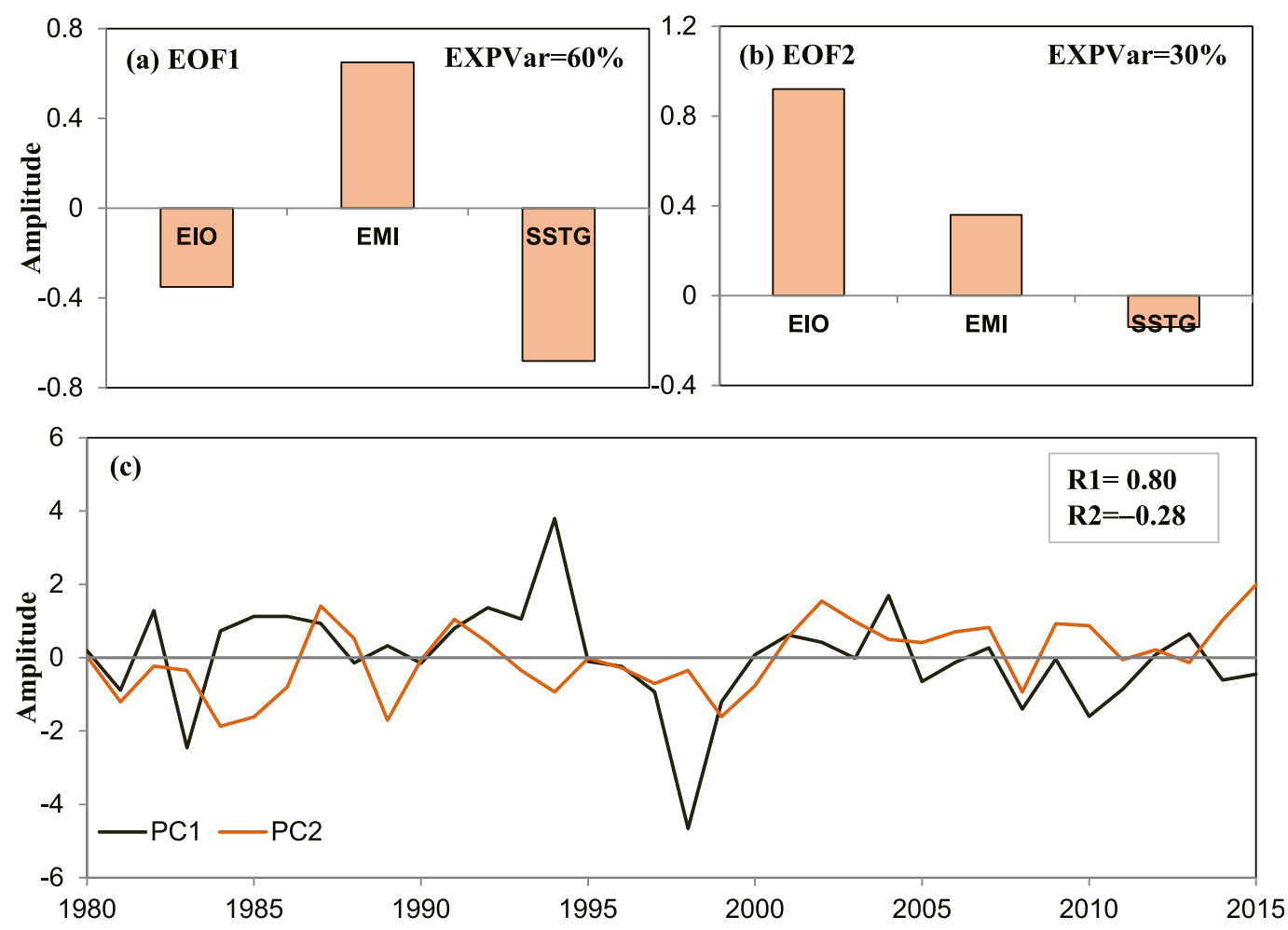

FIG. 6. The (a) first and (b) second MV-EOF modes of the summer EIO, the summer EMI, and the spring SSTG, and (c) their corresponding principal components (PCs). In (c), R1 (R2) indicates correlation coefficient between PC1 (PC2) and TCGF over the WNP in the typhoon season.

SST factors affect the interannual variability of TCGF as a whole and what their relative importance is. To address these questions, three methods-MV-EOF analysis, multiple linear regression, and the EFAGEFA method-were used to estimate the individual and combined contributions of the key SST factors in the Indo-Pacific Ocean to the WNP TCGF in the typhoon season. Results from those analyses are discussed in this section. Note that it is our great interest to evaluate the quantitative contributions by all three key SST factors to the interannual variability of WNP TCGF.

First, we applied the MV-EOF analysis to the normalized time series of the summer EIO index, the summer EMI, and the spring SSTG index, with results for the first two leading modes of the MV-EOFs shown in Fig. 6. The first MV-EOF mode, which accounts for $60 \%$ of the total variance, shows a positive anomaly of the EMI and negative anomalies of both the EIO index and the SSTG index. This coupled mode is in full accord with the correlations of the WNP TCGF with the three individual key SST factors discussed in section 3 . The correlation between the first principal component (PC1) and the TCGF is as high as 0.80 , which is statistically significant well above the $99 \%$ confidence level. This high correlation between the PC1 and the TCGF suggests that the three key SST factors in the IndoPacific Ocean as a whole predominantly contributed to the interannual variability of WNP TCGF. The second MV-EOF mode, which accounts for $30 \%$ of the total variance, is characterized by positive anomalies of both the EIO index and the EMI, and negative anomalies of the SSTG index. Especially, in the second mode the EIO shows the greatest amplitude with more than 2.5 times of the second greatest amplitude of EMI. The correlation coefficient between the second principal component (PC2) and the WNP TCGF is -0.28 , only significant at the $90 \%$ confidence level. This suggests that the second coupled mode is dominated by the EIO SSTA and is linked weakly to WNP TCGF. Note that in the first two leading modes the EMI exhibits uniformly the opposite sign to the SSTG index. This might be associated with the close relationship between the EMI and the SSTG, a point that will be discussed later.

Second, we performed a multiple linear regression for WNP TCGF using the three key SST factors. Figure 7 shows time series of the observed and regressed TCGFs during 1980-2015. We can see that the regressed TCGFs using the three key SST factors reproduce well the observed TCGFs, with their correlation coefficient being as high as 0.85 , which is statistically significant above the 


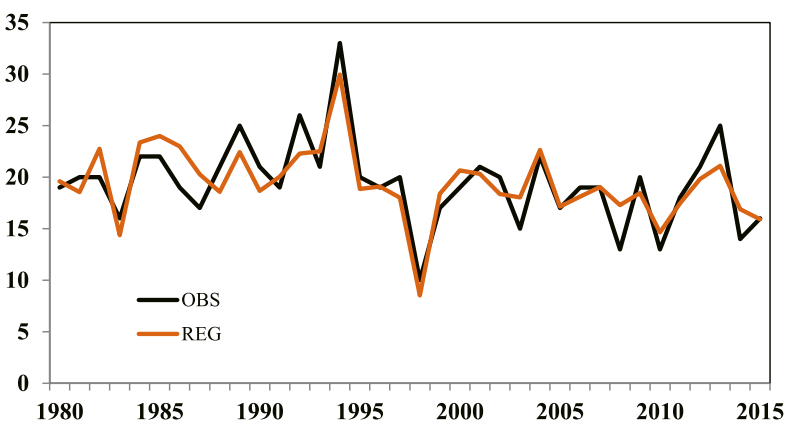

FIG. 7. Interannual variations of the observed TCGF based on the CMA best track data (black) and the regressed TCGF in the typhoon season with respect to the three key SST factors based on the multiple linear regression model (red) during 1980-2015. The correlation coefficient between them is 0.85 , which is significant at the $99 \%$ confidence level.

$99 \%$ confidence level, and with a deviation as low as 1.8, much less than one standard deviation (4.8). That is, the combination of the three key SST factors can explain $72 \%$ of the total variance of the WNP TCGF during the typhoon season in the period 1980-2015, which is much higher than any of their individual factors $(38.4 \%$ for the EIO, 33.6\% for the EMI, and 50.4\% for the SSTG).

Third, the relative importance of the three key SST factors was examined using the LMG method as introduced in section 2. We found that among the three factors the EIO, the EMI, and the SSTG contribute to $38 \%, 23 \%$, and $39 \%$, respectively, all statistically significant above the $95 \%$ bootstrap confidence level. This means that the SSTG and the EIO have similar contributions with the former slightly greater than the latter, while the EMI contributes the least. The above results are also consistent with those based on the multiple linear regression, in which the SSTG was the first selected predictor with an explained variance of $50.4 \%$, the EIO was the second selected predictor leading to the explained variance increasing to $70.0 \%$, and the EMI was finally selected with an extra improvement of $2 \%$. We further examined the spatial distributions of the correlations between the individual SST factors as well as their combination and the TCGF in the typhoon season in the period $1980-2015$ in each $10^{\circ} \times 10^{\circ}$ grid box (Fig. 8). Here, the TCGF was first binned into $10^{\circ} \times 10^{\circ}$
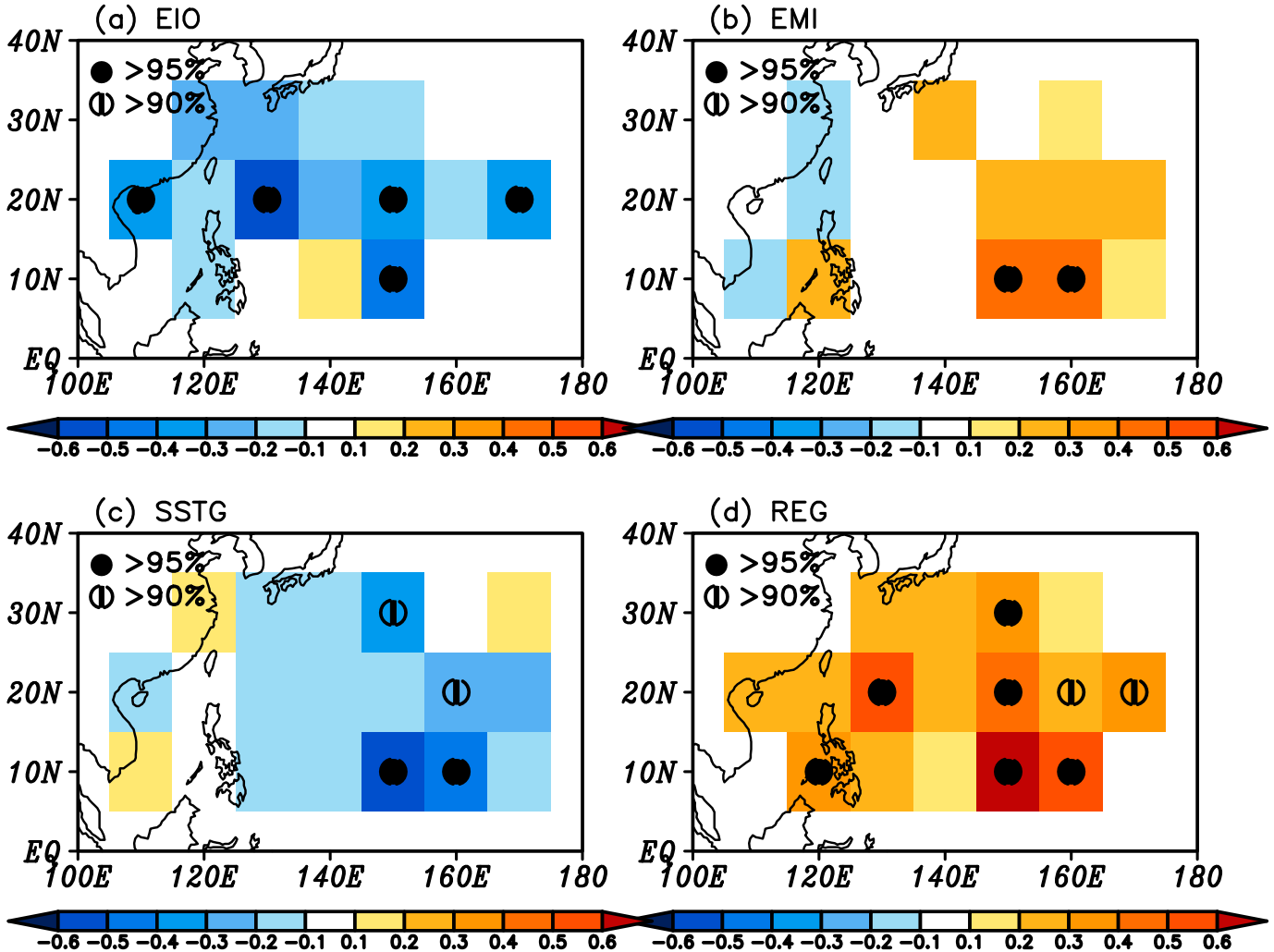

FIG. 8. Correlation coefficients between (a) the summer EIO, (b) the summer EMI, (c) the spring SSTG, and (d) a combination of all three, and the WNP TCGF in the typhoon season in each $10^{\circ} \times 10^{\circ}$ grid box from the CMA TC best track data during 1980-2015. The solid (hollow) dots indicate the correlation significant at the 95\% (90\%) confidence level. 
TABLE 2. Correlation matrix among the May EIO index, the summer EIO index, the summer EMI, and the spring SSTG index for the period 1980-2015. Coefficients significant at the $95 \%$ confidence level $( \pm 0.33)$ are shown in boldface.

\begin{tabular}{lcccc}
\hline \hline & $\begin{array}{c}\text { EIO } \\
\text { (May) }\end{array}$ & $\begin{array}{c}\text { EIO } \\
\text { (summer) }\end{array}$ & $\begin{array}{c}\text { EMI } \\
\text { (summer) }\end{array}$ & $\begin{array}{c}\text { SSTG } \\
\text { (spring) }\end{array}$ \\
\hline EIO (May) & $\mathbf{1}$ & & & \\
EIO (summer) & $\mathbf{0 . 8 8}$ & $\mathbf{1}$ & & \\
EMI (summer) & -0.11 & -0.14 & $\mathbf{1}$ & \\
SSTG (spring) & 0.19 & 0.28 & $\mathbf{- 0 . 6 9}$ & $\mathbf{1}$ \\
\hline
\end{tabular}

grid box, namely, the total number of TCs that formed in this box during the typhoon season in a year. Consistent with the total TCGF shown in Fig. 7, the combination of the three SST factors shows significant correlations with the gridded TCGF over most of the WNP (Fig. 8d), in particular in the region east of $140^{\circ} \mathrm{E}$ where almost all correlations are significant over $95 \%$ confidence level, while those over the SCS are relatively weak. Among the individual factors, the EIO is negatively correlated with the TCGF, significant over most of the WNP (Fig. 8a). This suggests that the EIO contributes to the basinwide interannual variability of WNP TCGF, consistent with previous studies of Zhan et al. (2011a,b). The SSTG is also negatively correlated with the basinwide TCGF, but mostly significant in the region east of $140^{\circ} \mathrm{E}$ (Fig. 8b). In contrast, the EMI only affects TCGF in the southeast quadrant of the WNP (Fig. 8c).

An issue arises as to whether the three SST factors are independent of each other or not. To address this issue, we calculated the correlation matrix among the summer EIO index, the summer EMI, and the spring SSTG index for the period 1980-2015 (Table 2). We can see that the EIO is not significantly correlated with either the EMI or the SSTG index, suggesting that the EIO can be considered being independent of other two SST factors. However, the EMI and the SSTG are highly correlated, with the correlation coefficient of -0.69 , significant above the $99 \%$ confidence level. This close relationship can be understood by the process that was used to explain how the spring SSTG affects TC genesis over the WNP in the typhoon season by Zhan et al. (2013). Zhan et al. (2013) found that the negative spring SSTG anomaly can produce an anomalous cross-equatorial pressure gradient, low-level northward cross-equatorial flow and tropical westerlies over the central-western Pacific. It is the anomalous westerlies induced by the spring SSTG that lead to anomalous local equatorial downwelling and seasonal warming in the CP in summer, and vice versa (see Figs. 4c and 5).

To further reveal the possibly involved interactions among the three key SST factors in affecting TCGF over the WNP, we conducted regression analyses to show the response of the low-level circulation over the WNP to the three key SST factors. Figure 9 shows the regressed seasonal-mean $850-\mathrm{hPa}$ wind fields in the typhoon season with respect to the spring SSTG index with the original data, with the EIO signal removed, with the EMI signal removed, and with both the EIO and the EMI signals removed using Eq. (1). Consistent with previous studies (Zhan et al. 2013; Zhao et al. 2016), when the spring SSTG was above normal (positive anomaly; Fig. 9a), the easterly anomalies covered the tropical WNP with an anomalous anticyclone over the main TC genesis region, inhibiting TC genesis over the WNP. After the EIO signal was removed (Fig. 9b), the easterly anomalies and the anomalous anticyclone in response to the SSTG were still significant and similar. However, after the EMI signal was removed (Figs. 9c and 9d), although overall the regressed low-level circulations were similar to those with the EMI signal retained (Fig. 9a), the response was largely suppressed with few areas being significant at the $95 \%$ confidence level. These results further demonstrate that the EIO is independent of the SSTG, while the SSTG exerts a significant influence on the atmospheric circulation and thus TC genesis over the WNP partly through its regulation of the summer EMI. Since the summer EMI is largely triggered/regulated by the spring SSTG, it could not be considered as an independent factor.

Since the key SST factors in the Indo-Pacific Ocean selected in section 3 are not completely independent of each other as discussed above, we reexamined their individual contributions to the TCGF by separating the impacts of other factors based on the GEFA method. For a comparison, the EFA method was also conducted, which might mix the contributions from other related factors. Figure 10 shows the feedback coefficients of the responses of WNP TCGF in the typhoon season to the three SST factors based on the EFA and GEFA methods. Note that a negative (positive) response means that the TCGF will be below (above) normal when the SSTAs are positive (negative). The responses to the EIO based on the EFA and GEFA methods are similar, suggesting that the impact of the EIO on TCGF is independent of other two factors and plays an important role in modulating the interannual variability of TCGF over the WNP. The responses to the SSTG based on the EFA and GEFA methods remain significant and are the greatest. Especially, the response based on the GEFA method becomes stronger than that based on the EFA method. In sharp contrast, the response to the EMI based on the EFA method differs completely from that based on the GEFA method. The response changes from significant positive based on the EFA method to insignificant negative based on the GEFA method, 
(a) SSTG SSTA

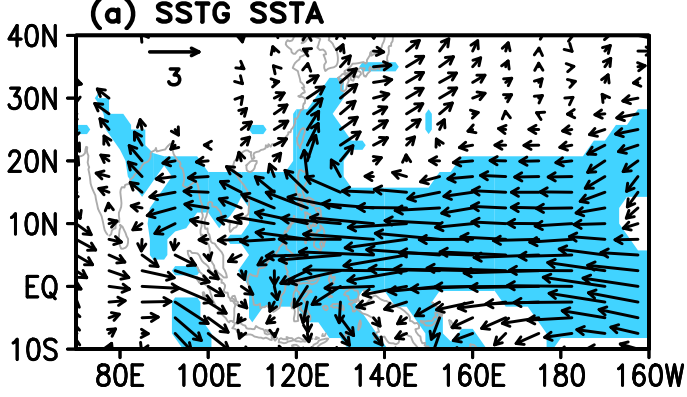

(c) Removing EMI SSTA

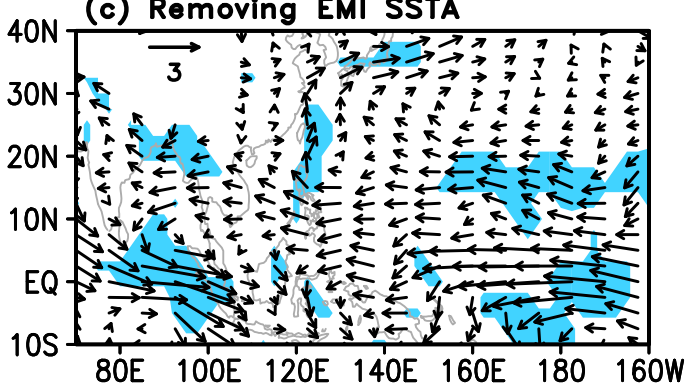

(b) Removing EIO SSTA

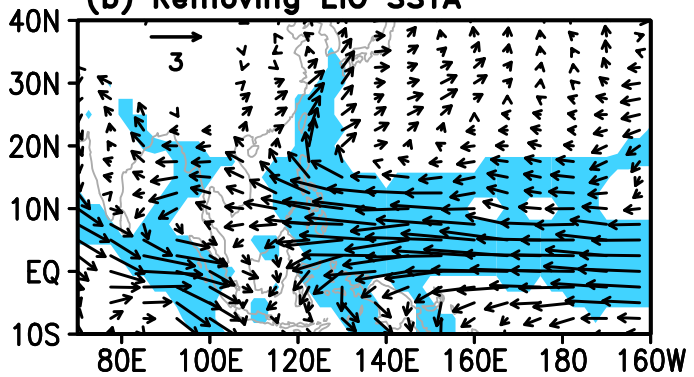

(d) Removing EIO \& EMI SSTAs

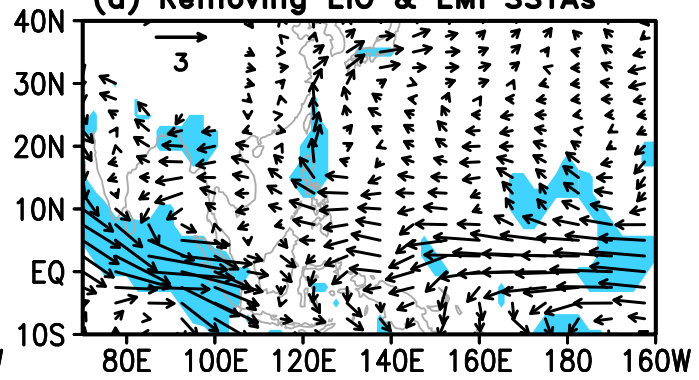

FIG. 9. Regressed seasonal-mean $850-\mathrm{hPa}$ wind fields $\left(\mathrm{m} \mathrm{s}^{-1}\right)$ in the typhoon season with respect to the spring SSTG index with (a) the original data, (b) the EIO signal removed, (c) the EMI signal removed, and (d) both the EIO and the EMI signals removed during 1980-2015. Areas that are statistically significant at the $95 \%$ confidence level based on the $\mathrm{F}$ test are shaded.

which is due to the close relationship between the EMI and the SSTG.

In summary, the interannual variability of TCGF in the typhoon season over the WNP is predominantly affected by the summer EIO and the spring SSTG, with a slightly greater contribution from the SSTG than that from the EIO. Although the summer EMI itself plays a significant role in modulating the interannual variability of WNP TCGF, it is mainly a response to the spring SSTG and thus is largely included in the spring SSTG. In this sense, compared with the summer EIO and the spring SSTG, the summer EMI is not a good predictor.

\section{A new statistical seasonal prediction model}

To verify how well the EIO and the spring SSTG contribute to the interannual variability of TCGF over the WNP, a statistical seasonal prediction model was developed using the multiple linear regression method. Hindcasts were performed based on the crossvalidation method using the model. Note that to facilitate the seasonal prediction the EIO index in May was used instead of the summer EIO index in developing the statistical prediction model. Indeed, we found that the EIO index has good persistence from spring to summer. The EIO index in May is highly correlated with that in summer, with the correlation coefficient as high as 0.88 (Table 2). Figure 11 shows the observed and the cross-validated estimates of the WNP TCGF in the typhoon season during 1980-2015. The correlation coefficient between the observed and predicted TCGFs reaches 0.72 , significant above the $99 \%$ confidence level. This suggests that the EIO and the SSTG not only significantly modulate the interannual variability of WNP TCGF but also are two predominant predictors for seasonal TCGF in the typhoon season over the WNP.

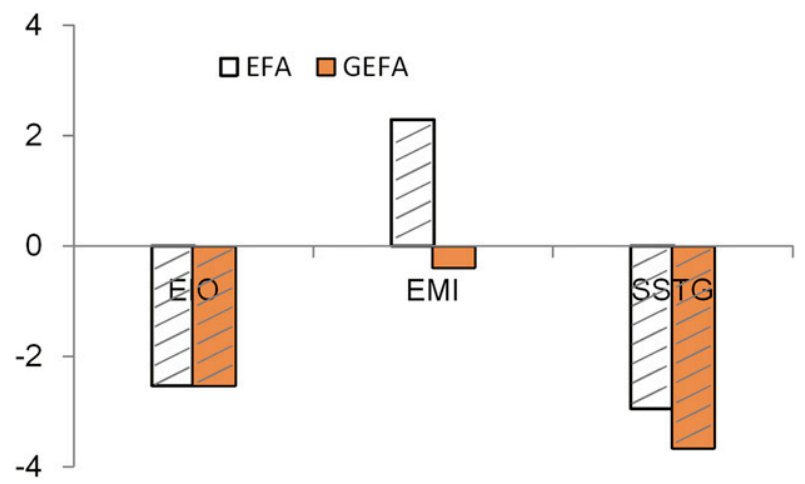

FIG. 10. The feedback coefficients of the responses of TCGF over the WNP in the typhoon season to the three key SST factors based on the EFA (white bar) and GEFA (orange bar) analyses. A slash indicates significance at the $95 \%$ confidence level by the Monte Carlo test. 


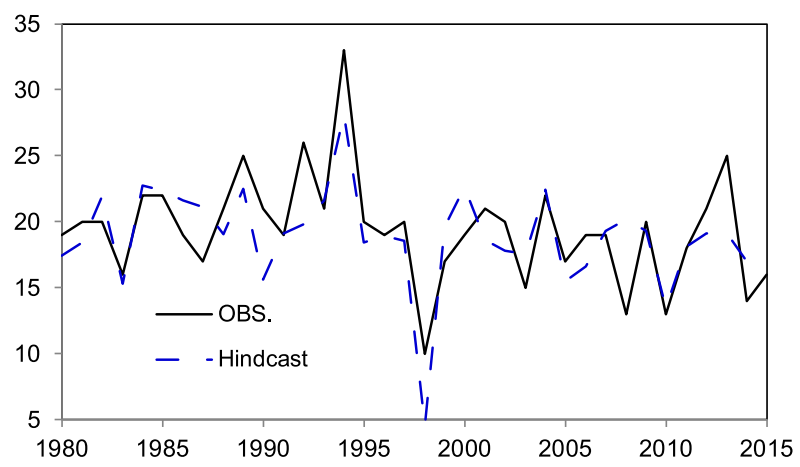

FIG. 11. Time series of the observed TCGF and the cross-validated estimates of the TCGF with the May EIO index and the spring SSTG index as predictors in the typhoon season for the period 1980-2015. The correlation between them is 0.72 , which is significant at the $99 \%$ confidence level.

To test the prediction skill of the newly developed statistical seasonal prediction model, we compared hindcasts of WNP TCGF from our statistical model and those from the ECMWF SEAS5. Since the ECMWF produced 6-month hindcasts each month for the period 1993-2015, our comparison focused on the seasonal prediction for June-November during 1993-2015. Figure 12 shows the observed and the hindcast TCGF from our new statistical model and that from the ECMWF SEAS5. Overall both hindcasts are in good agreement with observations. The correlation coefficient of our new model hindcast with the observed TC counts is 0.74 , significant above the $99 \%$ confidence level, while that of the ECMWF hindcast with the observed TC counts is 0.40 , only significant at the $90 \%$ confidence level. The root-mean-square errors (RMSEs) of our new model hindcast and the ECMWF hindcast are 3.1 and 4.2 , respectively, both smaller than the variance of 4.5 in observations. More interestingly, the new model can reproduce well the TCGFs in all three extreme years of 1994, 1998, and 2010, whereas the ECMWF only predicted the low TCGF in 2010.

DelSole and Shukla (2009) have shown that the prediction skill assessed by the cross-validation method can be an artifact. To reduce such a potential artifact, we further compared retrospective predictions of WNP TCGF from our statistical model based on the independent data and those from the ECMWF SEAS5 during 2004-15. For this purpose, in the new statistical model, the TC frequency in 2004 was predicted using the training data during 1982-2003 and that in 2005 using the training data during 1982-2004, and so on. From Fig. 12, we can see that the retrospective predictions from the new statistical model during 2004-15 (green) are closer to the observations (black) and better than the ECMWF

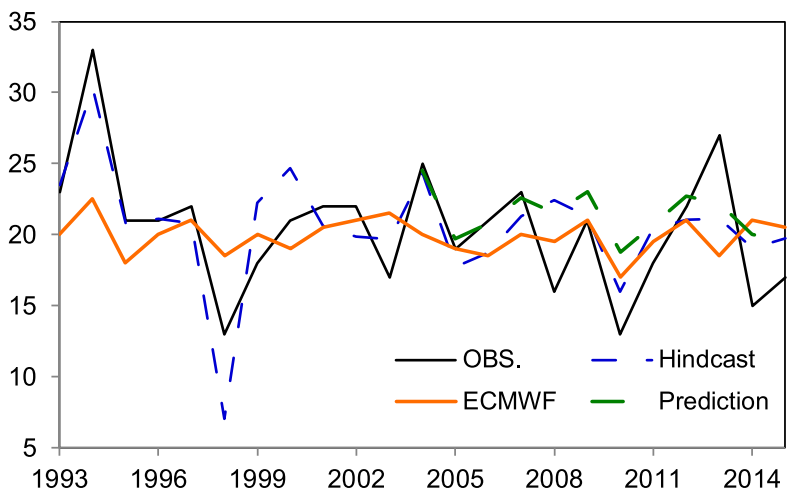

FIG. 12. Time series of the observed TCGF (black), the crossvalidated estimates of the new statistical model (blue), and the ECMWF hindcasts (orange) in June-November for the period 1993-2015. The dashed green curve represents the retrospective predictions based on the new statistical model from 2004 to 2015. The correlation coefficient between the observation and the hindcasts from the new statistical model (the ECMWF) is 0.74 (0.40), which is significant at the $99 \%(90 \%)$ confidence level. The correlation between the observation and the predictions from the new statistical model (ECMWF) during 2004-15 is 0.79 (0.15).

hindcasts (orange). The correlation coefficient of our new model retrospective predictions with the observed TC counts is 0.79 , significant above the $99 \%$ confidence level, while that of the ECMWF hindcasts with the observed TC counts is as low as 0.15 . The RMSEs of our new model retrospective predictions and the ECMWF hindcasts are 3.3 and 4.0, respectively. The above results are similar to those from the hindcast of the statistical model based on the cross-validation method discussed above. This strongly suggests that our new statistical model has better prediction skill than the ECMWF SEAS5.

\section{Conclusions and discussion}

The interannual variability of TCGF over the WNP is affected by many factors. Among them, the SSTAs in the Indo-Pacific Ocean have been shown to play critical role and thus received the most attention. However, most previous studies have focused on individual SST factors and the relative importance and contributions are unclear. Understanding these aspects is key to identify the physically based predictors for seasonal prediction of TC activity. In this study, we have evaluated quantitative contributions of the key SST factors in the Indo-Pacific Ocean to the WNP TCGF based on observational data analyses. Three SST factors in the Indo-Pacific Ocean have been identified to be key in modulating the WNP TCGF. They are the summer EIO SSTA, the summer ENSO Modoki, and the spring SSTG. Consistent with previous studies (e.g., Chen and Tam 2010; Zhan et al. 2011a,b; Zhan et al. 2013), the 
WNP TCGF was shown to be negatively correlated with the EIO index and the SSTG index, and positively correlated with the EMI.

Results from the MV-EOF analysis showed that the first MV-EOF mode, which accounts for $60 \%$ of the total variance, is in full accord with the individual correlations between the WNP TCGF and the three key SST factors. The combination of the three factors can explain $72 \%$ of the total variance of the WNP TCGF during the typhoon season in the period 1980-2015 based on the multiple linear regression analysis. This demonstrates that the combination of the three SST factors plays a critical role in modulating the interannual variability of TCGF over the WNP. Among the three factors, the SSTG and the EIO contribute predominantly to the interannual variability of TCGF, while the EMI contributes the least. This is because although the summer EMI itself plays an important role in modulating the interannual variability of WNP TCGF, it is primarily triggered by the spring SSTG and thus its role could be largely included in the spring SSTG. In this sense, the summer EMI is not a good predictor.

We have also developed a new statistical model, which can help verify how well the EIO and the spring SSTG contribute to the interannual variability of TCGF over the WNP. To facilitate seasonal prediction, the new statistical model uses the EIO index in May instead of in summer because of the good persistence of SSTA over the EIO. Results from both the hindcasts and the retrospective predictions demonstrate that the new statistical model based only on the two SST factors has good skill in reproducing the observed WNP TCGF and shows better skill than the ECMWF dynamical seasonal forecasting system (SEAS5). Therefore, this new statistical model can be applied to seasonal prediction of TC activity over the WNP.

Since the present study was limited to observational data analyses, we performed several sensitivity experiments using the atmospheric general circulation model ECHAM4.8 developed by the Max Planck Institute (Roeckner et al. 1996) to examine the combined effect of the three key SST factors on the low-level circulation over the WNP. We selected three extreme years for TCGF: one year (1994) with the highest and two years (1998 and 2010) with the lowest. Two experiments were designed for each year, including a control run with the observed SSTs in the corresponding year and a sensitivity run with the SSTs in the three key SST regions replaced by the 30-yr climatology of monthly mean SSTs. Each run had 30 ensembles but only the last 20 ensemble-mean results from June-October were analyzed. The difference between the control and sensitivity runs reflects the combined effect of the three key
SST factors, with the results shown in Fig. 13. We can see that the combined effect of the three key SST factors in the simulation generally resembles the observed anomalies in the corresponding years. Especially, the simulated patterns in 1994 and 1998 are very similar to those in observations. Note that although there is large bias over the SCS in 2010, anomalous easterlies over the tropical Pacific and an anomalous anticyclone over the WNP were well reproduced. These strongly indicate that these three key SST factors affect WNP TC activity by modulating the large-scale circulation. Note also that both the relationship between the SSTG and the EMI and their impacts on TC genesis involve complicated air-sea interaction, which deserves further study using a coupled model.

In addition, we noticed that Yu et al. (2016a) evaluated the relative contributions of major SST modes in the tropical Indian Ocean $\left(25^{\circ} \mathrm{S}-25^{\circ} \mathrm{N}, 40^{\circ}-100^{\circ} \mathrm{E}\right)$, the tropical North Pacific $\left(10^{\circ}-20^{\circ} \mathrm{N}, 150^{\circ} \mathrm{E}-140^{\circ} \mathrm{W}\right)$, and the tropical North Atlantic $\left(5^{\circ}-30^{\circ} \mathrm{N}, 80^{\circ}-20^{\circ} \mathrm{W}\right)$ to the interannual variability of TCGF over the WNP. They showed that the combination of the above three factors explains only $31.7 \%$ of the total variance and $25.8 \%$ of the interannual variability of WNP TCGF based on the regression analysis. In the GEFA method, the explained variances increased to $39.5 \%$ and $32.9 \%$, respectively, but still much less than $72 \%$ based on the three key SST factors in the Indo-Pacific Ocean identified in this study. In fact, we also examined the role of the SSTA over the tropical North Atlantic on the interannual variability of WNP TCGF. Consistent with previous studies (Huo et al. 2015; Yu et al. 2016b), the North Atlantic SSTA index and WNP TCGF are negatively correlated, with correlation coefficients of $-0.50,-0.47$, and -0.51 in the period 1980 2015 based on the CMA, JMA, and JTWC best track TC datasets, respectively. Here, the North Atlantic SSTA index was defined as the SSTA averaged in the region $5^{\circ}-30^{\circ} \mathrm{N}, 80^{\circ}-20^{\circ} \mathrm{W}$, the same as in $\mathrm{Yu}$ et al. (2016b). However, similar to the EMI, the North Atlantic SSTA is not an independent factor and its effect on the WNP TCGF can be accounted for by the summer EIO and the spring SSTG based on the multiple regression analysis (not shown). This strongly suggests that the SST factors over the Indo-Pacific Ocean predominantly modulate the interannual variability of TCGF over the WNP.

Finally, it should be pointed out that results from this study were based on the period 1980-2015. Many previous studies have shown that the relationships between various climate variations and TC activity are subject to changes over time (e.g., Zhan et al. 2014; Zhao et al. 2016). It is unclear whether the relative importance and their combined contribution of the key SST factors in the Indo-Pacific Ocean identified in this study would 
(a) 1994_OBS

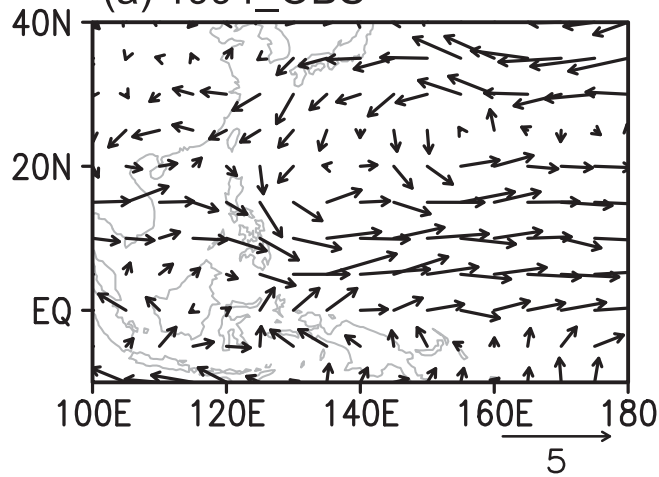

(b) 1998_OBS

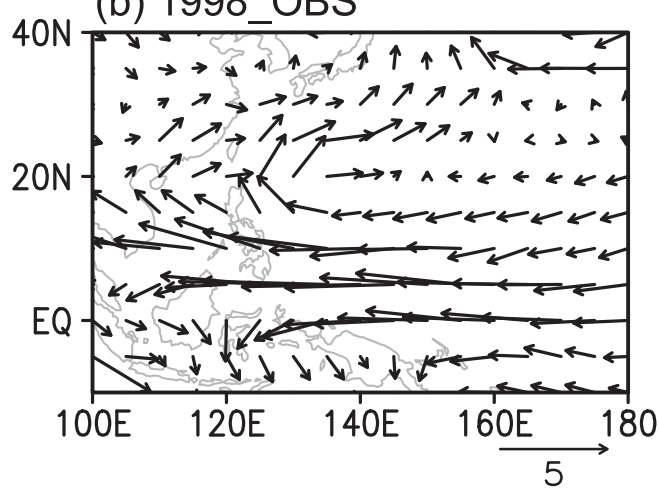

(c) 2010_OBS

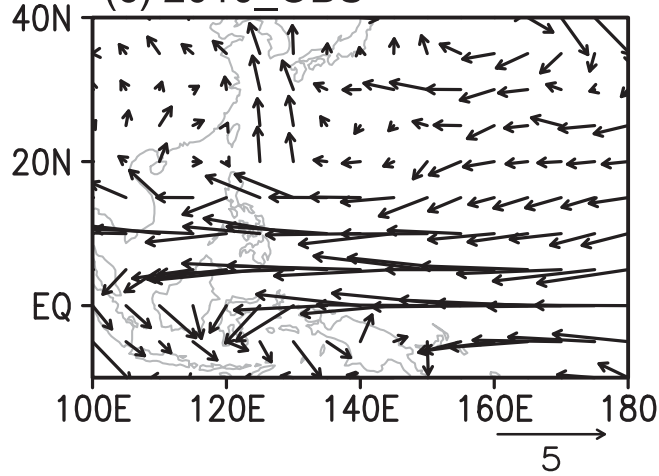

(d) 1994_Simulation

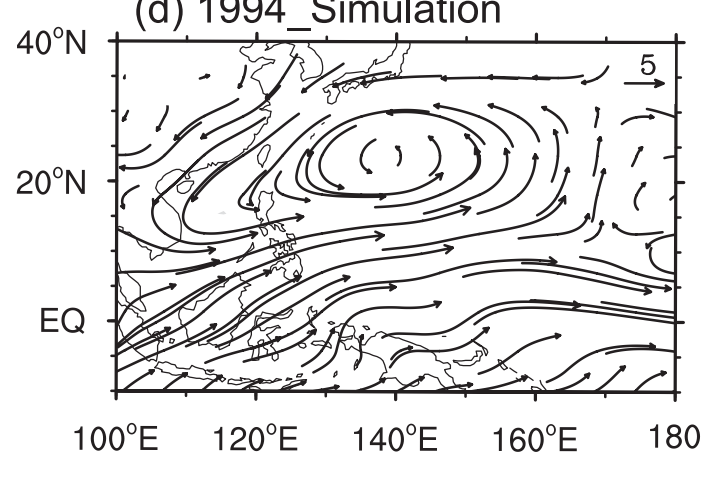

(e) 1998_Simulation

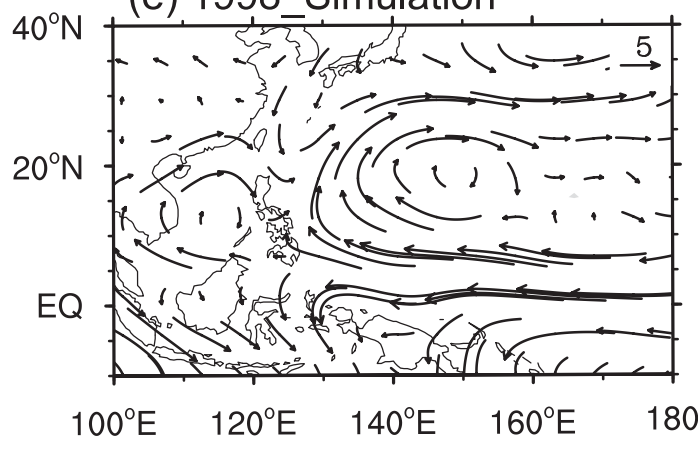

(f) 2010_Simulation

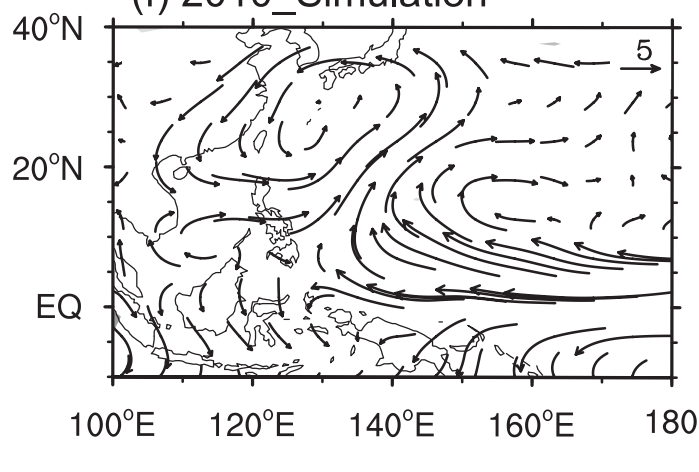

FIG. 13. The (left) observed and (right) simulated $850-\mathrm{hPa}$ wind anomalies $\left(\mathrm{m} \mathrm{s}^{-1}\right)$ in the typhoon season in (a),(d) 1994, (b),(e) 1998 and (c),(f) 2010. The differences between the control and sensitivity experiments reflect the combined effect of the three key SST factors on the low-level large-scale circulation and thus TCGF over the WNP.

change for a future warmed climate or for the evolving longer time scale variability, such as that related to the interdecadal Pacific Oscillation (Li et al. 2015; Hu et al. 2018). These are still open questions for future studies.

Acknowledgments. The authors are grateful to Drs. Congwen $\mathrm{Zhu}$, Zhiwei $\mathrm{Wu}$, and Guanghua Chen for their helpful comments on the manuscript. This study has been supported by the National Natural Science Foundation of China (Grants 41875114 and 41875057). Ruifen Zhan was supported in part by Open Research
Fund of the State Key Laboratory of Severe Weather, Chinese Academy of Meteorological Sciences (2017LASW-A01). The CMA best track TC dataset was downloaded from http://tcdata.typhoon.org.cn/. The JTWC best track TC dataset was from http://www. jma.go.jp/jma/jma-eng/jma-center/rsmc-hp-pub-eg/ besttrack.html. The JMA best track TC dataset was downloaded from http://www.jma.go.jp/jma/jma-eng/ jma-center/rsmc-hp-pub-eg/besttrack.html. The monthly ERSST v5 analyses were downloaded from https:// www.esrl.noaa.gov/psd/data/gridded/data.noaa.ersst.v5. 
html. The NCEP-NCAR reanalysis data were downloaded from https://www.esrl.noaa.gov/psd/data/gridded/ data.ncep.reanalysis.html. The ECMWF hindcast data of the TCF over the WNP were downloaded from https:// www.ecmwf.int/en/forecasts/charts.

\section{APPENDIX}

\section{List of Acronyms Used in the Main Text}

\begin{tabular}{|c|c|}
\hline CMA & China Meteorological Administration \\
\hline $\mathrm{CP}$ & Central Pacific \\
\hline ECMWF & $\begin{array}{l}\text { European Centre for Medium-Range } \\
\text { Weather Forecasts }\end{array}$ \\
\hline EFA & Equilibrium feedback assessment \\
\hline EIO & East Indian Ocean \\
\hline EMI & $\begin{array}{l}\text { El Niño-Southern Oscillation Modoki } \\
\text { index }\end{array}$ \\
\hline ENSO & El Niño-Southern Oscillation \\
\hline ERSST & $\begin{array}{l}\text { Extended reconstructed sea surface } \\
\text { temperature }\end{array}$ \\
\hline GEFA & Generalized EFA \\
\hline JMA & Japan Meteorological Agency \\
\hline JTWC & Joint Typhoon Warning Center \\
\hline MV-EOF & $\begin{array}{l}\text { Multivariate empirical orthogonal } \\
\text { function }\end{array}$ \\
\hline NCEP-NCAR & $\begin{array}{l}\text { National Centers for Environmental } \\
\text { Prediction-National Center for Atmo- } \\
\text { spheric Research }\end{array}$ \\
\hline NOAA & $\begin{array}{l}\text { National Oceanic and Atmospheric } \\
\text { Administration }\end{array}$ \\
\hline $\mathrm{PC}$ & Principal component \\
\hline SCS & South China Sea \\
\hline SEAS5 & ECMWF Seasonal Forecasting System 5 \\
\hline SST & Sea surface temperature \\
\hline SSTG & $\begin{array}{l}\text { SST gradient between the southwestern } \\
\text { Pacific and the western Pacific warm } \\
\text { pool }\end{array}$ \\
\hline SSTGA & SSTG anomaly \\
\hline SWP & Southwest Pacific east of Australia \\
\hline $\mathrm{TC}$ & Tropical cyclone \\
\hline TCGF & Tropical cyclone genesis frequency \\
\hline TS & Tropical storm \\
\hline WNP & Western North Pacific \\
\hline WWP & Western Pacific warm pool \\
\hline
\end{tabular}

\section{REFERENCES}

Ashok, K., Z. Guan, and T. A. Yamagata, 2003: A look at the relationship between the ENSO and the Indian Ocean dipole. J. Meteor. Soc. Japan, 81, 41-56, https://doi.org/10.2151/ jmsj.81.41.
_ S. K. Behera, S. A. Rao, H. Weng, and T. Yamagata, 2007: El Niño Modoki and its possible teleconnection. J. Geophys. Res., 112, C11007, https://doi.org/10.1029/2006JC003798.

Camargo, S. J., and A. H. Sobel, 2005: Western North Pacific tropical cyclone intensity and ENSO. J. Climate, 18, 29963006, https://doi.org/10.1175/JCLI3457.1.

Chan, J. C. L., 1985: Tropical cyclone activity in the northwest Pacific in relation to the El Niño/Southern Oscillation phenomenon. Mon. Wea. Rev., 113, 599-606, https://doi.org/ 10.1175/1520-0493(1985)113<0599:TCAITN > 2.0.CO;2.

_ 2000: Tropical cyclone activity over the western North Pacific associated with El Niño and La Niña events. J. Climate, 13, 2960-2972, https://doi.org/10.1175/1520-0442(2000)013<2960: TCAOTW $>2.0 . \mathrm{CO} ; 2$.

_ 2007: Interannual variations of intense typhoon activity. Tellus, 59A, 455-460, https://doi.org/10.1111/j.1600-0870.2007. 00241.x.

Chen, G., and C. Y. Tam, 2010: Different impacts of two kinds of Pacific Ocean warming on tropical cyclone frequency over the western North Pacific. Geophys. Res. Lett., 37, L01803, https:// doi.org/10.1029/2009GL041708.

Chen, T. C., S. P. Weng, N. Yamazaki, and S. Kiehne, 1998: Interannual variation in the tropical cyclone formation over the western North Pacific. Mon. Wea. Rev., 126, 1080-1090, https:// doi.org/10.1175/1520-0493(1998)126<1080:IVITTC>2.0.CO;2.

- S. Y. Wang, and M. C. Yen, 2006: Interannual variation of tropical cyclone activity over the western North Pacific. J. Climate, 19, 5709-5720, https://doi.org/10.1175/ JCLI3934.1.

Chia, H. H., and C. F. Ropelewski, 2002: The interannual variability in the genesis location of tropical cyclones in the northwest Pacific. J. Climate, 15, 2934-2944, https://doi.org/ 10.1175/1520-0442(2002)015<2934:TIVITG > 2.0.CO;2.

DelSole, T., and J. Shukla, 2009: Artificial skill due to predictor screening. J. Climate, 22, 331-345, https://doi.org/10.1175/ 2008JCLI2414.1.

Du, Y., L. Yang, and S. P. Xie, 2011: Tropical Indian Ocean influence on northwest Pacific tropical cyclones in summer following strong El Nino. J. Climate, 24, 315-322, https://doi.org/ 10.1175/2010JCLI3890.1.

Frankignoul, C., A. Czaja, and B. L'Heveder, 1998: Air-sea feedback in the North Atlantic and surface boundary conditions for ocean models. J. Climate, 11, 2310-2324, https://doi.org/ 10.1175/1520-0442(1998)011<2310:ASFITN > 2.0.CO;2.

Gill, A. E., 1980: Some simple solutions for heat-induced tropical circulation. Quart. J. Roy. Meteor. Soc., 106, 447-462, https:// doi.org/10.1002/qj.49710644905.

Grömping, U., 2006: Relative importance for linear regression in R: The package relaimpo. J. Stat. Softw., 17, 1-27, https://doi.org/ 10.18637/jss.v017.i01.

Hu, F., T. Li, J. Liu, M. Bi, and M. Peng, 2018: Decrease of tropical cyclone genesis frequency in the western North Pacific since 1960s. Dyn. Atmos. Oceans, 81, 42-50, https://doi.org/10.1016/ j.dynatmoce.2017.11.003.

Huo, L. W., P. W. Guo, S. N. Hameed, and D. C. Jin, 2015: The role of tropical Atlantic SST anomalies in modulating western North Pacific tropical cyclone genesis. Geophys. Res. Lett., 42, 2378-2384, https://doi.org/10.1002/2015GL063184.

Jiang, Z., H. Yang, Z. Liu, Y. Wu, and N. Wen, 2014: Assessing the influence of regional SST modes on the winter temperature in China: The effect of tropical Pacific and Atlantic. J. Climate, 27, 868-879, https://doi.org/10.1175/JCLI-D-1200847.1. 
Kalnay, E., and Coauthors, 1996: The NCEP/NCAR 40-Year Reanalysis Project. Bull. Amer. Meteor. Soc., 77, 437-471, https:// doi.org/10.1175/1520-0477(1996)077<0437:TNYRP>2.0.CO;2.

Kim, H. M., P. J. Webster, and J. A. Curry, 2011: Modulation of North Pacific tropical cyclone activity by three phases of ENSO. J. Climate, 24, 1839-1849, https://doi.org/10.1175/2010JCLI3939.1.

Lander, M., 1994: An exploratory analysis of the relationship between tropical storm formation in the western North Pacific and ENSO. Mon. Wea. Rev., 122, 636-651, https://doi.org/ 10.1175/1520-0493(1994)122<0636:AEAOTR>2.0.CO;2.

Li, W., L. Li, and Y. Deng, 2015: Impact of the interdecadal Pacific oscillation on tropical cyclone activity in the North Atlantic and eastern North Pacific. Sci. Rep., 5, 12358, https://doi.org/ 10.1038/srep12358

Lindeman, R., P. Merenda, and R. Gold, 1980: Introduction to Bivariate and Multivariate Analysis. Scott Foresman, 444 pp.

Liu, Z. Y., and L. X. Wu, 2004: Atmospheric response to North Pacific SST: The role of ocean-atmosphere coupling. J. Climate, 17, 1859-1882, https://doi.org/10.1175/15200442(2004)017<1859:ARTNPS > 2.0.CO;2.

— N. Wen, and Y. Liu, 2008: On the assessment of nonlocal climate feedback. Part I: The generalized equilibrium feedback assessment. J. Climate, 21, 134-148, https://doi.org/ 10.1175/2007JCLI1826.1.

Michaelsen, J., 1987: Cross-validation in statistical climate forecast models. J. Climate Appl. Meteor., 26, 1589-1600, https:// doi.org/10.1175/1520-0450(1987)026<1589:CVISCF > 2.0.CO;2.

Pu, X., Q. Chen, Q. Zhong, R. Ding, and T. Liu, 2019: Influence of the North Pacific Victoria mode on western North Pacific tropical cyclone genesis. Climate Dyn., 52, 245-256, https://doi.org/ 10.1007/s00382-018-4129-z.

Ramage, C. S., and A. M. Hori, 1981: Meteorological aspects of El Niño. Mon. Wea. Rev., 109, 1827-1835, https://doi.org/10.1175/ 1520-0493(1981)109<1827:MAOEN > 2.0.CO;2.

R Core Team, 2014: R: A language and environment for statistical computing. http://www.R-project.org.

Roeckner, E., and Coauthors, 1996: The atmospheric general circulation model ECHAM-4: Model description and simulation of present-day climate. MPI Rep. 218, 90 pp., https:// www.mpimet.mpg.de/fileadmin/publikationen/Reports/MPIReport_218.pdf.

Smith, T. M., and R. W. Reynolds, 2004: Improved extended reconstruction of SST (1854-1997). J. Climate, 17, 2466-2477, https://doi.org/10.1175/1520-0442(2004)017<2466:IEROS> 2.0.CO;2.

Tao, L., L. Wu, Y. Wang, and J. Yang, 2012: Influences of tropical Indian Ocean warming and ENSO on tropical cyclone activity over the western North Pacific. J. Meteor. Soc. Japan, 90, 127-144, https://doi.org/10.2151/jmsj.2012-107.

Vitart, F., J. L. Anderson, and W. F. Stern, 1997: Simulation of interannual variability of tropical storm frequency in an ensemble of GCM integrations. J. Climate, 10, 745-760, https:// doi.org/10.1175/1520-0442(1997)010<0745:SOIVOT>2.0.CO;2.

Wang, B., 1992: The vertical structure and development of the ENSO anomaly mode during 1979-1989. J. Atmos. Sci., 49, 698-712, https://doi.org/10.1175/1520-0469(1992)049<0698: TVSADO $>2.0 . \mathrm{CO} ; 2$.

, and J. C. L. Chan, 2002: How strong ENSO events affect tropical cyclone activity over the western North Pacific. J. Climate, 15, 1643-1658, https://doi.org/10.1175/15200442(2002)015<1643:HSEEAT>2.0.CO;2.
Wang, H., J.-K. Schemm, A. Kumar, W. Wang, L. Long, M. Chelliah, G. D. Bell, and P. Peng, 2009: A statistical forecast model for Atlantic seasonal hurricane activity based on the NCEP dynamical seasonal forecast. J. Climate, 22, 44814500, https://doi.org/10.1175/2009JCLI2753.1.

Wu, L., H. Zhang, J. Chen, and T. Feng, 2018: Impact of two types of El Niño on tropical cyclones over the western North Pacific: Sensitivity to location and intensity of Pacific warming. J. Climate, 31, 1725-1742, https://doi.org/10.1175/JCLI-D-17-0298.1.

Yu, J., C. Chen, T. Li, X. Zhao, H. Xue, and Q. Sun, 2016a: Contribution of major SSTA modes to the climate variability of tropical cyclone genesis frequency over the western North Pacific. Quart. J. Roy. Meteor. Soc., 142,1171-1181, https://doi.org/10.1002/qi.2722.

- T. Li, Z. Tan, and Z. Zhu, 2016b: Effects of tropical North Atlantic SST on tropical cyclone genesis in the western North Pacific. Climate Dyn., 46, 865-877, https://doi.org/10.1007/ s00382-015-2618-x.

Zhan, R. F., and Y. Wang, 2016: CFSv2-based statistical prediction for seasonal accumulated cyclone energy (ACE) over the western North Pacific. J. Climate, 29, 525-541, https://doi.org/ 10.1175/JCLI-D-15-0059.1.

_, , and X.-T. Lei, 2011a: Contributions of ENSO and East Indian Ocean SSTA to the interannual variability of northwest Pacific tropical cyclone frequency. J. Climate, 24, 509-521, https://doi.org/10.1175/2010JCLI3808.1.

,-- , and C.-C. Wu, 2011b: Impact of SSTA in East Indian Ocean on the frequency of northwest Pacific tropical cyclones: A regional atmospheric model study. J. Climate, 24, 62276242, https://doi.org/10.1175/JCLI-D-10-05014.1.

,$- \ldots$, and M. Ying, 2012: Seasonal forecasts of tropical cyclone activity over the western North Pacific: A review. Trop. Cyclone Res. Rev., 1, 307-324, https://doi.org/10.6057/ 2012TCRR03.07.

— — - and M. Wen, 2013: The SST gradient between the southwestern Pacific and the western Pacific warm pool: A new factor controlling the northwestern Pacific tropical cyclone genesis frequency. J. Climate, 26, 2408-2415, https:// doi.org/10.1175/JCLI-D-12-00798.1.

- - , and L. Tao, 2014: Intensified impact of East Indian Ocean SST anomaly on tropical cyclone genesis frequency over the western North Pacific. J. Climate, 27, 8724-8739, https://doi.org/10.1175/JCLI-D-14-00119.1.

_ B. D. Chen, and Y. H. Ding, 2018: Impacts of SST anomalies in the Indian-Pacific basin on the Northwest Pacific tropical cyclone activities during three super El Niño years. J. Oceanol. Limnol., 36, 20-32, https://doi.org/10.1007/ s00343-018-6321-8.

Zhang, W., G. A. Vecchi, H. H. Murakami, G. G. Villarini, and L. L. Jia, 2016: The Pacific meridional mode and the occurrence of tropical cyclones in the western North Pacific. J. Climate, 29, 381-398, https://doi.org/10.1175/JCLI-D-15-0282.1.

Zhao, J. W., R.-F. Zhan, Y. Wang, and L. Tao, 2016: Intensified interannual relationship between tropical cyclone genesis frequency over the northwest Pacific and the SST gradient between the southwest Pacific and the western Pacific warm pool since the mid-1970s. J. Climate, 29, 3811-3830, https:// doi.org/10.1175/JCLI-D-15-0729.1.

Zhou, B. T., and X. Cui, 2011: Sea surface temperature east of Australia: A predictor of tropical cyclone frequency over the western North Pacific? Chin. Sci. Bull., 56, 196-201, https:// doi.org/10.1007/s11434-010-4157-5. 